\title{
Surgical Resection Length and Harvested Lymph Nodes in Colon Cancer
}

\author{
Mustafa Taner Bostanci and Ibrahim Yilmaz \\ Department of General Surgery, University of Health Sciences, Dışkapı Yldırım Beyazıt Training and Research Hospital, Ankara, Turkey
}

\begin{abstract}
Objective: To determine the relationship between resected specimen length and tumor location, the number of LN harvested (LNh), and the positive LN ratio (LNR) in colon cancer.

Study Design: A descriptive study.

Place \& Duration of Study: Department of General Surgery, University of Health Sciences, Dışkapı Yıldırım Beyazıt Training and Research Hospital, Ankara, Turkey, between January 2009 and December 2019.

Methodology: Colon specimens resected for colon cancer were evaluated retrospectively, in terms of tumor location, type of surgery, resected colon length, LNh and the number of metastatic LN, based on hospital records. Chi-square test, Kruskal-Wallis along with Dunn-Bonferroni post hoc tests were applied. The lymph node ratio (LNR) (= ratio of LN+ to LNh), the number of lymph nodes per unit distance $(\mathrm{LNh} / \mathrm{cm})$, the ratio of $L N R$ to length of specimen $(\mathrm{LNR} / \mathrm{cm})$ were evaluated.

Results: The rate of $\geq 12 \mathrm{LNh}$ in 644 colon cancer patients was $81.4 \%$. The length of colon specimen and the number of harvested lymph nodes (LNh) were higher in patients, who underwent subtotal colectomy (StC), compared to patients who underwent right and left hemicolectomy (RhC and LhC, $\mathrm{p}<0.001$ ). Inadequate $\mathrm{LNh}$ was more common in LhC patients $(p<0.001)$. The ratio of the number of $\mathrm{LNh}$ to the length of the resected specimen $(\mathrm{LNh} / \mathrm{cm})$ was higher in $\mathrm{RhC}$ and $\mathrm{LhC}$ patients than StC patients $(p<0.001)$. LNR and LNR/cm were higher in LhC patients, though mean specimen length was shorter in LhC patients $(p<0.05)$. The number of LNh had a direct proportion with the resected specimen length; however, the $L \mathrm{Nh} / \mathrm{cm}$ and $\mathrm{LNR} / \mathrm{cm}$ ratios decreased in $>50 \mathrm{~cm}$ length specimen patients $(p<0.001)$.

Conclusion: Central LN dissection and vascular high ligation, according to tumor site are more efficient than the length of the resected specimen for an adequate LN dissection in colon cancers.
\end{abstract}

Key Words: Colon cancer, Harvested lymph node, Specimen length, Adequate dissection

How to cite this article: Bostanci MT, Yilmaz I. Surgical Resection Length and Harvested Lymph Nodes in Colon Cancer. J Coll Physicians Surg Pak 2021; 31(07):798-804.

\section{INTRODUCTION}

Colon cancer is one of the most common causes of cancer deaths in western countries, and surgery is still the gold standard curative treatment option. The most important prognostic factor for colon cancer is lymph node involvement during surgical treatment. ${ }^{1,2}$ The presence of nodal metastasis is an important marker for determining the postoperative adjuvant treatment decision and for disease-free survival. ${ }^{3}$ Therefore, correct nodal staging is essential to determine the proper treatment management in colon cancerpatients. ${ }^{4,5}$

Correspondence to: Dr. Ibrahim Yilmaz, Department of General Surgery, University of Health Sciences, Dişkapl Ylldırım Beyazit Training and Research Hospital, Ankara, Turkey

E-mail:dribrahimyilmaz@yahoo.com

Received: February 26, 2021; Revised: May 03, 2021;

Accepted: June 01, 2021

DOI: https://doi.org/10.29271/jcpsp.2021.07.798
The number of lymph nodes harvested from the resected colon segment has a key role in adequate nodal staging and is associated with many factors; such as, the patient's clinical features, surgeon's operative technique and the pathologist's microscopic evaluation. ${ }^{6-8}$ Over the years, the optimisation of some of the factors affecting them has been achieved with the oncological principles determined by surgeons in colorectal surgery and the chemical cleaning methods applied by pathologists in mesentery adipose tissue. The American Society of Clinical Oncology, the Cancer Commission of the American College of Surgeons, the American College of Pathologists, the National Comprehensive Cancer Network, and the National Cancer Institute have reported that at least 12 lymph nodes should be dissected with surgical specimens in colon cancer cases in order to standardise surgical and postoperative treatment. ${ }^{9 \cdot 12}$

Considering that there may be a direct relationship between the resected colon specimen length and the mesentery size and the number of lymph nodes; the aim of this study was to evaluate the relationship between the length of resected colon and the number of dissected lymph nodes in colon cancer patients, in terms of the number of metastatic lymph nodes harvested and lymph node ratio. 


\section{METHODOLOGY} hospital (27.11.2017/43-24). This retrospective study included colon cancer patients, who underwent elective or emergency curative surgery between January 2009 and December 2019 at University of Health Sciences, Dışkapı Yıldırım Beyazıt Training ated due to benign diseases (ulcerative colitis, noninvasive colon polyps, familial polyposis syndrome, etc.), non-adenomatous colon neoplasm (neuroendocrine tumor, stromal tumor), synchronous colon tumors, and rectal tumors (tumors located up to $15 \mathrm{~cm}$ from the anal entrance), were excluded. Demographic data, type of surgery, location of the tumor, surgery and pathology reports of the patients were analyed retrospectively from the database of this hospital. The histopathological findings, the degree of differentiation, the invasion depth of the tumor (T status), the presence of lymph node involvement ( $\mathrm{N}$ number of metastatic lymph nodes $(\mathrm{LN}+)$ and the length of the resected colon $(\mathrm{cm})$ have been analysed from pathology reports. The lymph node ratio (LNR) (= ratio of $L N+$ to $L N h)$ and the number of lymph nodes per unit distance $(\mathrm{LNh} / \mathrm{cm})$ were analysed. The average number of positive lymph nodes per unit distance were evaluated by the ratio of LNR to length of specimen (LNR/cm).

Neoplasm was evaluated according to the $8^{\text {th }}$ American Joint Committee on Cancer TNM classification and removal of $<12$ lymph nodes was considered as an inadequate lymph node dissection..$^{13}$ Cecum, ascending colon, hepatic flexure and transverse colon tumors were defined as right colon tumors, splenic flexure, descending colon and sigmoid colon tumors were defined as left colon tumors, and tumors located at the level of peritoneal reflection and rectosigmoid junction were defined as rectosigmoid tumors. Surgical resections were grouped as right hemicolectomy (RhC), left hemicolectomy (including sigmoidectomy, segmental colon resection) (LhC), and subtotal colectomy (StC). Although partial terminal ileum resection was included in RhC, the ileocecal junction was accepted as the proximal surgical margin. Cecal necrosis due to an obstructed mass located in the left colon, serosal abrasion in the cecum and a large-based proximal colon-located polyp accompanying the left colon tumor were defined as surgical indications of StC. Lymph node dissection was performed by resection of colon segment with mesentery containing vascular and lymphatic vessels together in one piece, according to the location of the tumor. The operations were performed by applying high ligation to the major vessels. The authors evaluated the relationship between the performed surgical techniques with the number of adequate harvested lymph nodes and the length of the colon segment that had to be resected to reach adequate lymph node dissection ( $\geq 12$ ) for RhC, LhC and StC.

Data were analysed by using SPSS (SPSS Inc., an IBM Company, Chicago, IL) for Microsoft Windows 17.0. Chi-square test was used to evaluate qualitative data and were given as frequencies
Approval was obtained from the local ethics committee of our and Research Hospital, Ankara, Turkey. Patients who were operstatus), the total number of lymph nodes harvested (LNh), the

and percentages (gender, staging, classification, etc.) as well as descriptive statistical methods (mean, standard deviation, median, $25^{\text {th }}$ percentile and $75^{\text {th }}$ percentile). Kruskal-Wallis along with Dunn-Bonferroni post hoc tests were applied because parametric test conditions could not be provided in quantitative data. The receiver operating characteristic (ROC) curve was used to determine the best cut-off for the amount of bowel to resect in order to achieve an adequate number of lymph nodes (minimum 12) according to the type of operation performed. The statistical significance level was taken as 0.05 inall tests.

\section{RESULTS}

The demographic data, tumor localisation, TNM classification, pathological diagnosis and LNh of 644 cases are listed in Table 1. The emergency cases were $29.8 \%$ of the patients, and all of them had an obstructive tumor. The presence of distant metastases was diagnosed by preoperative radiological imaging or intraoperative exploration. Histopathologically, most of the patients had moderately differentiated or NOS (not otherwise specified) tumors. The authors determined that $18.6 \%$ of the patients had inadequate LN dissection.

Table I: Demographic characteristics of patients and neoplasms.

\begin{tabular}{|c|c|}
\hline Variables & n (\%) \\
\hline \multicolumn{2}{|l|}{ Gender } \\
\hline Male & $397(61.6 \%)$ \\
\hline Female & $247(38.4 \%)$ \\
\hline \multicolumn{2}{|l|}{ Age (years) } \\
\hline$<65$ & $317(49.2 \%)$ \\
\hline$\geq 65$ & $327(50.8 \%)$ \\
\hline \multicolumn{2}{|l|}{ Elective/Emergency } \\
\hline Emergency & $192(29.8 \%)$ \\
\hline Elective & $452(70.2 \%)$ \\
\hline \multicolumn{2}{|l|}{ Tumor Localisation } \\
\hline Right & $210(32.6 \%)$ \\
\hline Left & $387(60.1 \%)$ \\
\hline Rectosigmoid & $47(7.3 \%)$ \\
\hline \multicolumn{2}{|l|}{ Tumor } \\
\hline T1 & $25(3.9 \%)$ \\
\hline T2 & $60(9.3 \%)$ \\
\hline T3 & $407(63.2 \%)$ \\
\hline T4 & $152(23.6 \%)$ \\
\hline \multicolumn{2}{|l|}{ Node } \\
\hline N0 & $286(44.4 \%)$ \\
\hline N1 & $153(23.8 \%)$ \\
\hline N2 & $85(13.2 \%)$ \\
\hline $\mathrm{Nx}$ & $120(18.6 \%)$ \\
\hline \multicolumn{2}{|l|}{ Metastasis } \\
\hline M0 & $592(91.9 \%)$ \\
\hline M1 & $52(8.1 \%)$ \\
\hline Liver (M1a) & $38(5.9 \%)$ \\
\hline Peritoneum (M1c) & $5(0.8 \%)$ \\
\hline Liver+ Peritoneum(M1c) & $9(1.4 \%)$ \\
\hline \multicolumn{2}{|l|}{ Histopathology } \\
\hline NOS (not otherwise specified) & $555(86.2 \%)$ \\
\hline Mucinous carsinom & $89(13.8 \%)$ \\
\hline \multicolumn{2}{|l|}{ Differentiation } \\
\hline Well & $81(12.6 \%)$ \\
\hline Moderate & $484(75.2 \%)$ \\
\hline Poor & $41(6.4 \%)$ \\
\hline Undefined & $38(5.9 \%)$ \\
\hline \multicolumn{2}{|l|}{ Harvested Lymph Nodes (LNh) } \\
\hline$<12$ & $120(18.6 \%)$ \\
\hline$\geq 12$ & $524(81.4 \%)$ \\
\hline
\end{tabular}


Table II: Comparison of surgical resections types.

\begin{tabular}{|c|c|c|c|c|}
\hline & Right hemicolectomy (RhC) & Left hemicolectomy (LhC) & Subtotal colectomy (StC) & $\mathbf{p}$ \\
\hline n (\%) & $210(32.6 \%)$ & $383(59.5 \%)$ & $51(7.9 \%)$ & \\
\hline $\begin{array}{l}\text { Age } \\
\text { mean } \pm \text { sd } \\
\text { median (IQR 25\%-75\%) }\end{array}$ & $\begin{array}{c}63.68 \pm 12.06 \\
65(55-73)\end{array}$ & $\begin{array}{c}63.77 \pm 11.81 \\
64(56-72)\end{array}$ & $\begin{array}{c}65.24 \pm 10.72 \\
67(58-74)\end{array}$ & 0.594 \\
\hline \multicolumn{4}{|l|}{ Gender } & \multirow{3}{*}{0.918} \\
\hline Male & $127(60.5 \%)$ & $238(62.1 \%)$ & $32(62.7 \%)$ & \\
\hline Female & $83(39.5 \%)$ & $145(37.9 \%)$ & $19(37.3 \%)$ & \\
\hline \multicolumn{4}{|l|}{ Elective/Emergency } & \multirow{3}{*}{$<0.001$} \\
\hline Emergency & $47(22.4 \%)$ & $104(27.2 \%)$ & $41(80.4 \%)$ & \\
\hline Elective & $163(77.6 \%)$ & $279(72.8 \%)$ & $10(19.6 \%)$ & \\
\hline \multicolumn{4}{|l|}{ Tumor Localisation } & \multirow{4}{*}{$<0.001$} \\
\hline Right & $210(100.0 \%)$ & 0 & 0 & \\
\hline Left & 0 & $341(89.0 \%)$ & $46(90.2 \%)$ & \\
\hline Rectosigmoid & 0 & $42(11.0 \%)$ & $5(9.8 \%)$ & \\
\hline \multicolumn{4}{|l|}{ Tumor } & \multirow{5}{*}{0.047} \\
\hline $\mathrm{T} 1$ & $4(1.9 \%)$ & $20(5.2 \%)$ & $1(2.0 \%)$ & \\
\hline T2 & $19(9.0 \%)$ & $40(10.4 \%)$ & $1(2.0 \%)$ & \\
\hline T3 & $138(65.7 \%)$ & $239(62.4 \%)$ & $30(58.8 \%)$ & \\
\hline T4 & $49(23.3 \%)$ & $84(21.9 \%)$ & $19(37.2 \%)$ & \\
\hline $\begin{array}{l}\text { Resected Colon Length }{ }^{\text {a }}(\mathbf{c m}) \\
\text { mean } \pm \text { sd } \\
\text { median (IQR 25\%-75\%) }\end{array}$ & $\begin{array}{c}29.07 \pm 15.53 \\
25(19-34)\end{array}$ & $\begin{array}{c}21.63 \pm 11.42 \\
19(15-25)\end{array}$ & $\begin{array}{l}97.67 \pm 23.37 \\
100(80-110) \\
\end{array}$ & $<0.001$ \\
\hline $\begin{array}{l}\text { Surgical Border (cm) } \\
\text { mean } \pm \text { sd } \\
\text { median (IQR 25\%-75\%) }\end{array}$ & $\begin{array}{l}7.29 \pm 5.13 \\
6(4-9.35) \\
\end{array}$ & $\begin{array}{l}4.97 \pm 2.3 \\
4.2(3-6.5) \\
\end{array}$ & $\begin{array}{c}11.93 \pm 9.81 \\
10(4.5-16) \\
\end{array}$ & $<0.001$ \\
\hline \multicolumn{4}{|l|}{ LNh* (\%) } & \multirow{3}{*}{$<0.001$} \\
\hline$\geq 12$ & $190(90.5 \%)$ & $284(74.2 \%)$ & $50(98.0 \%)$ & \\
\hline$<12$ & $20(9.5 \%)$ & $99(25.8 \%)$ & $1(2.0 \%)$ & \\
\hline $\begin{array}{l}\text { LNh }^{\mathbf{b}^{\mathbf{b}}} \\
\text { mean } \pm \text { sd } \\
\text { median (IQR 25\%-75\%) }\end{array}$ & $\begin{array}{c}23.67 \pm 12.26 \\
21(15-30)\end{array}$ & $\begin{array}{c}18.12 \pm 10.39 \\
16(11-23)\end{array}$ & $\begin{array}{c}30.47 \pm 19.6 \\
25(17-37)\end{array}$ & $<0.001$ \\
\hline $\begin{array}{l}\mathbf{L N h} / \mathbf{c m}^{\mathbf{c}} \\
\text { mean } \pm \text { sd } \\
\text { median (IQR 25\%-75\%) }\end{array}$ & $\begin{array}{c}0.96 \pm 0.60 \\
0.8(0.53-1.22)\end{array}$ & $\begin{array}{c}0.93 \pm 0.57 \\
0.82(0.54-1.22)\end{array}$ & $\begin{array}{c}0.32 \pm 0.2 \\
0.25(0.17-0.38)\end{array}$ & $<0.001$ \\
\hline LN+ patients $* *(\%)$ & $87(41.4 \%)$ & $156(40.7 \%)$ & $21(41.2 \%)$ & \multirow{3}{*}{$<0.001$} \\
\hline$\geq 12$ & $81(93.1 \%)$ & $115(73.7 \%)$ & $21(100.0 \%)$ & \\
\hline$<12$ & $6(6.9 \%)$ & $41(26.3 \%)$ & $0(0 \%)$ & \\
\hline $\begin{array}{l}\text { LNR*** } \\
\text { mean } \pm \text { sd } \\
\text { median (IQR 25\%-75\%) }\end{array}$ & $\begin{array}{c}0.18 \pm 0.20 \\
0.09(0.05-0.24)\end{array}$ & $\begin{array}{c}0.25 \pm 0.25 \\
0.16(0.08-0.3)\end{array}$ & $\begin{array}{c}0.16 \pm 0.17 \\
0.1(0.06-0.25)\end{array}$ & 0.003 \\
\hline $\begin{array}{l}\text { LNR/cm } \\
\text { mean } \pm \text { sd } \\
\text { median (IQR 25\%-75\%) }\end{array}$ & $\begin{array}{c}0.0078 \pm 0.010 \\
0.003(0.002-0.01)\end{array}$ & $\begin{array}{c}0.013 \pm 0.014 \\
0.008(0.004-0.016)\end{array}$ & $\begin{array}{c}0.0017 \pm 0.013 \\
0.001(0.0004-0.003)\end{array}$ & $<0.001$ \\
\hline
\end{tabular}

LhC was the most performed surgery (59.5\%), and no difference was found between resection types in terms of age and gender ( $p: 0.594$ and 0.918 ). StC group was mostly consisted of emergency cases $(p<0.001)$. In all three groups, most of the patients had T3 tumors.

Table III: Comparison of resected colon lengths. 


\begin{tabular}{|c|c|c|c|c|c|}
\hline & \multicolumn{5}{|c|}{ Resected Colon Length $(\mathrm{cm})$} \\
\hline & $\begin{array}{l}\text { Groupl: } \\
0-10\end{array}$ & $\begin{array}{l}\text { Group2: } \\
11-30\end{array}$ & $\begin{array}{l}\text { Group3: } \\
\text { 31-50 }\end{array}$ & $\begin{array}{l}\text { Group4: } \\
>50\end{array}$ & $\mathbf{p}$ \\
\hline n (\%) & $21(3.3 \%)$ & $455(70.6 \%)$ & $89(13.8 \%)$ & $79(12.3 \%)$ & \\
\hline $\begin{array}{l}\text { Age } \\
\text { mean } \pm \text { sd } \\
\text { median (IQR } \\
25 \%-75 \%)\end{array}$ & $\begin{array}{l}66.29 \pm 10.57 \\
66(58.5-73.5)\end{array}$ & $\begin{array}{l}63.98 \pm 11.95 \\
65(56-73)\end{array}$ & $\begin{array}{l}62.65 \pm 12.0 \\
64(55-70)\end{array}$ & $\begin{array}{l}63.67 \pm 11.17 \\
64(56-73)\end{array}$ & 0.656 \\
\hline Gender & & & & & \multirow{3}{*}{0.979} \\
\hline Male & $12(57.1 \%)$ & $281(61.8 \%)$ & $55(61.8 \%)$ & $49(62.0 \%)$ & \\
\hline Female & $9(42.9 \%)$ & $174(38.2 \%)$ & $34(38.2 \%)$ & $30(38.0 \%)$ & \\
\hline \multicolumn{5}{|c|}{ Elective/Emergency(\%) } & \multirow{3}{*}{$<0.001$} \\
\hline Emergency & $5(23.8 \%)$ & $102(22.4 \%)$ & $32(36.0 \%)$ & $53(.67 .1 \%)$ & \\
\hline Elective & $16(76.2 \%)$ & $353(77.6 \%)$ & $57(64.0 \%)$ & $26(32.9 \%)$ & \\
\hline \multicolumn{5}{|c|}{ Tumor Localisation } & \multirow{4}{*}{$<0.001$} \\
\hline Right & $2(9.5 \%)$ & $135(29.7 \%)$ & $56(62.9 \%)$ & $17(21.5 \%)$ & \\
\hline Left & $12(57.1 \%)$ & $287(63.1 \%)$ & $31(34.8 \%)$ & $57(72.2 \%)$ & \\
\hline Rectosigmoid & $7(33.3 \%)$ & $33(7.2 \%)$ & $2(2.2 \%)$ & $5(6.3 \%)$ & \\
\hline \multicolumn{5}{|l|}{$\mathbf{T}$} & \multirow{5}{*}{0.003} \\
\hline T1 & $2(9.5 \%)$ & $22(4.8 \%)$ & $0(0 \%)$ & $1(1.3 \%)$ & \\
\hline $\mathrm{T} 2$ & $5(23.8 \%)$ & $43(9.5 \%)$ & $9(10.1 \%)$ & $3(3.8 \%)$ & \\
\hline T3 & $10(47.6 \%)$ & $295(64.8 \%)$ & $54(60.7 \%)$ & $48(60.7 \%)$ & \\
\hline T4 & $4(19.0 \%)$ & $95(20.9 \%)$ & $26(29.2 \%)$ & $27(34.2 \%)$ & \\
\hline \multicolumn{5}{|l|}{ Surgery } & \multirow{4}{*}{$<0.001$} \\
\hline RhC & $2(9.5 \%)$ & $135(29.7 \%)$ & $56(62.9 \%)$ & $17(21.5 \%)$ & \\
\hline LhC & $19(90.5 \%)$ & $320(70.3 \%)$ & $33(37.1 \%)$ & $11(13.9 \%)$ & \\
\hline StC & $0(0 \%)$ & $0(0 \%)$ & $0(0 \%)$ & $51(64.6 \%)$ & \\
\hline $\begin{array}{l}\text { Surgical Border } \\
(\mathbf{c m}) \\
\text { mean } \pm s d \\
\text { median (IQR } \\
25 \%-75 \%)\end{array}$ & $\begin{array}{l}2.51 \pm 0.25 \\
2(1.75-2.9)\end{array}$ & $\begin{array}{l}5.0 \pm 2.5 \\
4.5(3-6.5)\end{array}$ & $\begin{array}{l}8.49 \pm 4.7 \\
8.5(4.5-11.4)\end{array}$ & $\begin{array}{l}12.13 \pm 9.42 \\
10(5-16)\end{array}$ & $<0.001$ \\
\hline \multicolumn{5}{|l|}{ LNh (\%) } & \multirow{3}{*}{$<0.001$} \\
\hline$\geq 12$ & $10(47.6 \%)$ & $355(78.0 \%)$ & $82(92.1 \%)$ & $77(97.5 \%)$ & \\
\hline$<12$ & $11(52.4 \%)$ & $100(22.0 \%)$ & $7(7.9 \%)$ & $2(2.5 \%)$ & \\
\hline $\begin{array}{l}\text { LNh }^{*} \\
\text { mean } \pm \text { sd } \\
\text { median (IQR } \\
25 \%-75 \%)\end{array}$ & $\begin{array}{l}11.48 \pm 6.96 \\
11(6.5-14.5)\end{array}$ & $\begin{array}{l}19.24 \pm 10.72 \\
17(12-24)\end{array}$ & $\begin{array}{l}23.40 \pm 11.33 \\
23(14-30)\end{array}$ & $\begin{array}{l}30.24 \pm 18.24 \\
25(18-37)\end{array}$ & $<0.001$ \\
\hline $\begin{array}{l}\text { LNh/cma } \\
\text { mean } \pm \text { sd } \\
\text { median (IQR } \\
25 \%-75 \%)\end{array}$ & $\begin{array}{l}1.24 \pm 0.76 \\
1.37(0.7-1.5)\end{array}$ & $\begin{array}{l}1.01 \pm 0.59 \\
0.88(0.62-1.27)\end{array}$ & $\begin{array}{l}0.63 \pm 0.32 \\
0.58(0.4-0.81)\end{array}$ & $\begin{array}{l}0.36 \pm 0.23 \\
0.33(0.2-0.43)\end{array}$ & $<0.001$ \\
\hline $\begin{array}{l}\text { LN+ patients** } \\
(\%)\end{array}$ & $4(19.0 \%)$ & $177(38.9 \%)$ & $50(56.2 \%)$ & $33(41.8 \%)$ & \multirow{3}{*}{$<0.001$} \\
\hline$\geq 12$ & $2(50.0 \%)$ & $137(77.4 \%)$ & $46(92.0 \%)$ & $32(97.0 \%)$ & \\
\hline$<12$ & $2(50.0 \%)$ & $40(22.6 \%)$ & $4(8.0 \%)$ & $1(3.0 \%)$ & \\
\hline $\begin{array}{l}\text { LNR*** } \\
\text { mean } \pm \text { sd } \\
\text { median (IQR } \\
25 \%-75 \%)\end{array}$ & $\begin{array}{l}0.17 \pm 0.12 \\
0.12(0.1-0.3)\end{array}$ & $\begin{array}{l}0.23 \pm 0.24 \\
0.15(0.07-0.3)\end{array}$ & $\begin{array}{l}0.20 \pm 0.22 \\
0.095(0.06-0.3)\end{array}$ & $\begin{array}{l}0.19 \pm 0.22 \\
0.12(0.05-0.22)\end{array}$ & 0.435 \\
\hline $\begin{array}{l}\text { LNR/cm } \\
\text { mean } \pm \text { sd } \\
\text { median (IQR } \\
25 \%-75 \%)\end{array}$ & $\begin{array}{l}0.02 \pm 0.01 \\
0.012(0.01-0.03)\end{array}$ & $\begin{array}{l}0.01 \pm 0.01 \\
0.008(0.004-0.016)\end{array}$ & $\begin{array}{l}0.007 \pm 0.011 \\
0.003(0.002-0.008)\end{array}$ & $\begin{array}{l}0.003 \pm 0.005 \\
0.001(0.0005-0.003)\end{array}$ & $<0.001$ \\
\hline
\end{tabular}

StC was performed in two early stage left colon tumors due to synchronous proximally located broad-based polypoid lesion, and pathology reported as T1 tumor in one case and T2 tumor in the other, villous adenoma in one and tubulovillous adenoma with high grade dysplasia in the other. The length of the resected colon specimen was longer in the patients in the StC group than the other two groups $(p<0.001)^{*}$. However, the length of the specimen resected in the RhC group was longer than in the LhC group $(p<0.001)$. The longest surgical margin length were in the StC group, the RhC group and the LhC group, respectively ( $p$ $<0.001)^{*}$. The ratio of adequate lymph node dissection in the RhC, LhC, and StC groups were $90.5 \%, 74.2 \%$ and $98.0 \%$, respectively. The $\mathrm{LNh}$ obtained in the StC group were higher 
than the other two groups ( $p<0.001)^{*}$, and the LNh obtained in the RhC group were higher than the LhC group ( $p$ $<0.001)^{*}$.

Metastatic LN was found $41 \%$ (264/644) of the patients, and among these patients inadequate lymph node dissection rate was the highest in the LhC group $(26.3 \%)(p<0.001)^{*}$. The $\mathrm{LNh} / \mathrm{cm}$ had the highest value in the RhC group and then in the LhC group, while the difference between the RhC and LhC groups and the StC group was significant ( $p$ $<0.001)^{*}$, the difference between the RhC and LhC groups were similar $(p=0.94)^{*}$. The LNR was the highest in the LhC group, therefore the LNR/cm was higher than in the other groups and, a statistically significant difference was found between the groups in terms of LNR and $L N R / \mathrm{cm}$. Comparison among different types of surgical resection according to lymph node dissection is listed in Table II.

The length of the resected specimen divided into 4 groups; Group1: 0-10cm, Group2: $11-30 \mathrm{~cm}$, Group3: $31-50 \mathrm{~cm}$, Group4 :> 50cm; and they were similar in terms of age and gender ( $p: 0.656$ and 0.979 ). The length of the specimen resected in emergency operations was mostly over $30 \mathrm{~cm}$; and Group 4 patients mostly underwent emergency operations. Group 1, Group 2 and Group 4 consisted of left colon tumors, while Group 3 consisted mostly right colon tumors. In all three groups, the majority of the patients were with T3 tumors. LhC ( $p<0.001$ ) for Group 1 and Group 2, RhC ( $p$ $<0.001)$ for Group 3 and StC $(p<0.001)$ for Group 4 were preferred resection type.

The length of the resected specimen had a direct proportion with the closest surgical margin distance to the tumor ( $p$ $<0.001)^{*}$. As the length of the resected specimen increased, the number of patients with $\geq 12$ lymph node dissection and the number of lymph nodes dissected increased $(p<0.001)^{*}$; however, the $\mathrm{LNh} / \mathrm{cm}$ ratio decreased. Although there was not statistically difference between Group 1 and Group 2 in terms of $\mathrm{LNh} / \mathrm{cm}$, but there was a difference between Group 1 and Group 2 with Group 3 and Group $4(p<0.001)^{*}$.

The rate of inadequate lymph node dissection decreased as the length of the resected specimen increased $(p<0.001)$ in patients with metastatic LN. The highest LNR was found in Group 2 ( $p: 0.435$ ) and the LNR/cm ratio decreased as the specimen length increased. Although there was not statistically significant difference between Group 1 and Group 2, the difference between Group 1 and Group 2 with Group 3 and Group 4 was significant for LNR/cm ( $p<0.001^{*}$ : adjusted using the Bonferroni correction).

The comparison of different specimen lengths, according to the number of lymph node dissected, is listed in Table III. The length of the colon for adequate LN dissection was found be $25.5 \mathrm{~cm}$ (sensitivity: $51.1 \%$, specificity: $75 \%$ ) for right colon tumors, and $22.75 \mathrm{~cm}$ (sensitivity: $38.7 \%$, specificity: $80.8 \%$ ) for left colon tumors.

\section{DISCUSSION}

Curative resection of colon tumors and accurate identification of positive lymph nodes are important in terms of staging the disease, postoperative management, prognosis, and survival rates have an inverse proportion with the number of dissected metastatic lymph nodes. ${ }^{14}$ The number of harvested lymph nodes can vary depending on patient-related factors (age, gender, tumor biology), surgeon-induced factors (surgeon's experience, type of surgery) and pathologist-derived factors (experience of the pathologist, specific dissection techniques). While patient-induced factors are not alterable, surgeon and pathologist originated factors are manageable. ${ }^{15,16}$ It has been reported that adequate lymph node dissection $(\mathrm{LNh} \geq 12$ ) in colon cancer is still at the level of $70-80 \% .{ }^{17,18}$ In this study, this rate was determined as $81.4 \%$ (524/644), comparable with the literature.

Radical techniques, such as mesocolic excision and high ligation of vascular structures, have been developed in colorectal cancer surgery for adequate LN dissection. In addition, the idea of 'longer colon resection, more dissected LN' seemed to be valid by many surgeons and some studies have shown that there is a direct proportion between the length of the resected specimen and the number of lymph nodes dissected. ${ }^{8,19}$ However, although the average length of the specimen resected varies according to the location of the tumor and the type of surgery performed, the localisation of the tumor also affects the number of lymph nodes dissected. ${ }^{20}$

There are many studies reported that the number of lymph nodes dissected in tumors located in the left colon and rectum is less than right or transvers colon located tumors. ${ }^{7,21}$ Studies have reported that the surgeon avoids a high anterior resection especially in left colon tumors located in the distal sigmoid and rectosigmoid, resulting in the resection of the shorter colon segment and therefore less lymph node dissection. ${ }^{22}$ In addition, the fact that the vascular anatomy allows the resection of a longer colon segment and wider mesentery in right colon tumors is seen as another factor in removing more lymph nodes in tumors located in the right colon compared to tumors located in the left colon. ${ }^{23}$ Microsatellite instability (MSI), which is an important pathway in tumor biology and detected in $20-25 \%$ of right colon tumors should be considered as another important factor, because MSI has been found to be associated with a high level of locoregional lymph nodes metastasis. ${ }^{24}$ In abdominoperineal resection and low anterior resection operations performed for rectal tumors, although the resected segment is long, less lymph node dissection than left colon tumor operations has been reported to be associated with preoperative chemoradiotherapy. ${ }^{25}$

The number of harvested lymph nodes was analysed, according to the resection type; and it was found that the length of the resected specimen and the number of lymph 
nodes harvested were higher in RhC than in LhC, similar with the literature. It is conclude that the longer right colon mesentery and the presence of dense lymph nodes in the ileocecal region cause this result. Besides, segmental resections of the colon (sigmoidectomy, segmental resection for splenic flexure tumor) can be associated with short specimen length.

The surgical margin was shorter in the LhC group where the number of rectosigmoid tumors was high compared to the other two groups in our study. We conclude that this situation is caused by the surgeon's avoidance of mesorectal dissection and an inferior anastomosis. However, it is noticed that this situation not only leads to a short surgical margin, but also to shorter specimen length and an increase in the number of inadequate lymph node dissection. Comparison of resection types showed that highest LNR was in the LhC group. Although the number of metastatic LN patients among the groups was relatively similar, the high LNR in these patients seemed to be an expected result due to the high number of patients with inadequate lymph node dissection in the LhC group. There are many studies indicating the prognostic importance of the LNR ratio, especially in stage 1-3 colorectal cancer patients. However, this view leads to the conclusion that prognostic evaluation would be more accurate in patient groups with $\geq 12$ lymph node dissection according to the LNR result.

Comparison of resected colon lengths showed that there was a direct proportion between length of the specimen and number of harvested $L N$, similar with the literature. It is found that the LNR is similar in different specimen lengths. However, considering that the definition of adequate lymph dissection is aimed to capture the possible metastatic lymph node, it is seen that the number of $L N+$ patients detected increases up to $50 \mathrm{~cm}$ specimen length, but this rate decreases when the specimen length is over $50 \mathrm{~cm}$. In this case, although specimen length and LNh have a linear relationship, it led to the conclusion that "more is not necessarily better" as stated by Amri et al. ${ }^{10}$.

There are a few studies indicating the minimum length of the colon specimen that needs to be resected for an adequate $L N$ dissection. Stracci et al. reported that a colon resection of at least $20 \mathrm{~cm}$ is required for an adequate LN dissection regardless of the location of the tumor. ${ }^{9}$ Gravante et al. stated that the specimen should be at least $36 \mathrm{~cm}$ in abdominoperineal resection and $42 \mathrm{~cm}$ in Hartmann's resection for an adequate LN dissection, especially for rectum and rectosigmoid tumors. ${ }^{7}$ The length of resected colon segment should be $25.5 \mathrm{~cm}$ in the RhC and $22.75 \mathrm{~cm}$ in the $\mathrm{LhC}$, in order to harvest $12 \mathrm{LN}$ with a low sensitivity and $>75 \%$ specifity.

The limitations of the study are that retrospective design and operations were performed by different surgeons that would affect the surgery type.

\section{CONCLUSION}

The length of the resected colon segment in colon tumors is associated with the number of harvested LN mathematically, but clinically anatomical location of the tumor, vascular and lymphatic anatomy are the major factors for the number of LN harvested, so colon tumor surgery should be done by oncological principles.

\section{ETHICAL APPROVAL:}

The study was approved by the local Ethics Committee of Dışkapı Yıldırım Beyazıt Training and Research Hospital, Ankara, Turkey (27.11.2017 / 43-24).

\section{CONFLICT OF INTEREST:}

The authors declared no conflict of interest.

\section{AUTHORS' CONTRIBUTION:}

MTB, IY: Material preparation, data collection and analysis. The first draft of the manuscript was written and all authors commented on previous versions of the manuscript; all authors read and approved the final manuscript; and contributed to the study conception and design.

\section{REFERENCES}

1. Chapuis PH, Dent OF, Fisher R, Newland RC, Pheils MT, Smyth $\mathrm{E}$, et al. A multivariate analysis of clinical and pathological variables in prognosis after resection of large bowel cancer. Br J Surg 1985; 72(9):698-702. doi: 10.1002/bjs. 1800720909.

2. Cohen AM, Tremiterra S, Candela F, Thaler HT, Sigurdson ER. Prognosis of node-positive colon cancer. Cancer 1991; 67(7):1859-1861. doi: 10.1002/1097-0142(19910401) 67:7<1859::aid-cncr2820670707>3.0.c0;2-a.

3. Chang GJ, Rodriguez-Bigas MA, Skibber JM, Moyer VA. Lymph node evaluation and survival after curative resection of colon cancer: Systematic review. J Natl Cancer Inst 2007; 99(6):433-41. doi: 10.1093/jnci/djk092.

4. Huh JW, Kim YJ, Kim HR. Distribution of lymph node metastases is an independent predictor of survival for sigmoid colon and rectal cancer. Ann Surg 2012; 255(1):70-8. doi: 10.1097/SLA.0b013e31823785f6.

5. Willaert W, Mareel M, Van De Putte D, Van Nieuwenhove Y, Pattyn P, Ceelen W. Lymphatic spread, nodal count and the extent of lymphadenectomy in cancer of the colon. Cancer Treat Rev 2014; 40(3):405-13. doi: 10.1016/j.ctrv.2013. 09.013.

6. Lavy R, Madjar-Markovitz H, Hershkovitz Y, Sandbank J, Halevy A. Influence of colectomy type and resected specimen length on number of harvested lymph nodes. Int J Surg 2015; 24(PT A):91-4. doi: 10.1016/j.ijsu.2015.11.011.

7. Gravante G, Parker R, Elshaer M, Mogekwu AC, Humayun N, Thomas K, et al. Lymph node retrieval for colorectal cancer: Estimation of the minimum resection length to achieve at least 12 lymph nodes for the pathological analysis. Int J Surg 2016; 25:153-7. doi: 10.1016/j.ijsu.2015.12.062.

8. Thorn CC, Woodcock NP, Scott N, Verbeke C, Scott SB, Ambrose NS. What factors affect lymph node yield in 
surgery for rectal cancer? Colorectal Dis 2004; 6(5):356-61. doi: 10.1111/j.1463-1318.2004.00670.x.

9. Stracci F, Bianconi F, Leite S, Liso A, La Rosa F, Lancellotta $V$, et al. Linking surgical specimen length and examined lymph nodes in colorectal cancer patients. Eur J Surgical Oncol (EJSO) 2016; 42(2):260-5. doi: 10.1016/j.ejso.2015. 11.017 .

10. Amri R, Klos CL, Bordeianou L, Berger DL. The prognostic value of lymph node ratio in colon cancer is independent of resection length. Am J Surg 2016; 212(2):251-7. doi: 10.1016/j.amjsurg.2015.10.037.

11. Altintas S, Bayrak M. Assessment of factors influencing lymph node count in colorectal cancer. J Coll Phys Surg Pak 2019; 29(12):1173-8. doi: 10.29271/jcpsp.2019.12.1173.

12. Orsenigo E, Gasparini G, Carlucci M. Clinicopathological factors influencing lymph node yield in colorectal cancer: A retrospective study. Gastroenterol Res Prac 2019; 2019:5197914. doi: 10.1155/2019/5197914.

13. Brunicardi FC, Andersen DK, Billiar TR, Dunn DL, Kao LS, Hunter JG, et al. Schwartz's principles of surgery. 10th ed. New York: McGraw-Hill Education; 2015: 1175-241.

14. Voyer TE, Sigurdson ER, Hanlon AL, Mayer RJ, Macdonald JS, Catalano PJ, et al. Colon cancer survival is associated with increasing number of lymph nodes analysed: A secondary survey of intergroup trial INT-0089. J Clin Oncol 2003; 21(15):2912-9. doi: 10.1200/JCO.2003.05.062.

15. Aan de Stegge WB, van Leeuwen BL, Elferink MA, de Bock $\mathrm{GH}$. The evaluation of more lymph nodes in colon cancer is associated with improved survival in patients of all ages. PLoS One 2016; 11(5): e0155608. doi: 10.1371/journal.pone.0155608.

16. Hernanz F, García-Somacarrera E, Fernández F. The assessment of lymph nodes missed in mesenteric tissue after standard dissection of colorectal cancer specimens. Colorectal Dis 2010; 12 (7 Online):57-60. doi: 10.1111/j.14631318.2009.01987.x.

17. Huh JW, Kim CH, Kim HR, Kim YJ. Factors predicting oncologic outcomes in patients with fewer than 12 lymph nodes retrieved after curative resection for colon cancer. J Surg
Oncol 2012; 105(2):125-9. doi: 10.1002/jso.22072.

18. Gehoff A, Basten O, Sprenger T, Conradi LC, Bismarck C, Bandorski $D$, et al. Optimal lymph node harvest in rectal cancer (UICC stages II and III) after preoperative 5-FU-based radiochemotherapy: Acetone compression is a new and highly efficient method. Am J Surgical Pathol 2012; 36(2): 202-13. doi: 10.1097/PAS.0b013e31823fa35b.

19. Weiss JM, Schumacher J, Allen GO, Neuman H, Lange EO, Loconte NK, et al. Adjuvant chemotherapy for stage II rightsided and left-sided colon cancer: Analysis of SEER-medicare data. Ann Surg Oncol 2014; 21(6):1781-91. doi: 10.1245/s10434-014-3631-8.

20. Gonsalves WI, Kanuri S, Tashi T, Aldoss I, Sama A, AlHowaidi I, et al. Clinicopathologic factors associated with lymph node retrieval in resectable colon cancer: A veterans' affairs central cancer registry (VACCR) database analysis. J Surg Oncol 2011; 104(6):667-71. doi: 10.1002/jso.21886.

21. Chou JF, Row D, Gonen M, Liu YH, Schrag D, Weiser MR. Clinical and pathologic factors that predict lymph node yield from surgical specimens incolorectal cancer: A population-based study. Cancer 2010; 116(11):2560-70. doi: 10.1002/cncr.25032.

22. Morikawa T, Tanaka N, Kuchiba A, Nosho K, Yamauchi M, Hornick JL, et al. Predictors of lymph node count in colorectal cancer resections: Data from US nationwide prospective cohort studies. Arch Surg 2012; 147(8):715-23. doi: 10.1001/archsurg.2012.353.

23. Nathan H, Shore AD, Anders RA, Wick EC, Gearhart SL, Pawlik TM. Variation in lymph node assessment after colon cancer resection: Patient, surgeon, pathologist, or hospital? J Gastrointest Surg 2011; 15(3):471-9. doi: 10.1007/ s11605-010-1410-9.

24. Søreide K, Nedrebø BS, Søreide JA, Slewa A, Korner H. Lymph node harvest in colon cancer: Influence of microsatellite instability and proximal tumor location. World J Surg 2009; 33(12):2695-703. doi: 10.1007/s00268-009-0255-4.

25. Damin DC, Rosito MA, Contu PC, Tarta C, Ferreira PR, Kliemann LM, et al. Lymph node retrieval after preoperative chemoradiotherapy for rectal cancer. J Gastrointest Surg 2012; 16(8):1573-80. doi: 10.1007/s11605-012-1916-4. 